\title{
Gulls of a feather do not sleep whenever-circadian rhythm of activity of black-headed gulls Chroicocephalus ridibundus during the incubation period
}

\author{
Piotr Indykiewicz ${ }^{1}$ (D) Dariusz Jakubas $^{2}$ (D) Julita Gerke ${ }^{3}$
}

Received: 13 January 2021 / Revised: 23 April 2021 / Accepted: 5 May 2021 / Published online: 29 May 2021

(c) The Author(s) 2021

\begin{abstract}
Many vertebrates exhibit a diel activity, steered by light-dark cycle. However, some colonial waterbirds, in that several species of gulls, are active not only in day hours but also at night. In this study, we aimed to investigate 24 h cycle of blackheaded gulls (BHG) Chroicocephalus ridibundus activity with focus on sleep behaviour. We expected that $24 \mathrm{~h}$ patterns of activity differ between colonies located in various habitats, and within a colony between nests located in the centre vs at the edge. We studied behaviour based on 9600 of $30 \mathrm{~s}$ videos from camera-traps taken in six colonies and data from 10 GPStracked individuals from one colony recorded during incubation. BHGs stayed active on average during $48.1 \%$ of a night, mainly spent on passive and active nest defence, and on nest maintenance. BHGs spent similar time on these activities in day hours. Individuals breeding in the colony centre slept at night longer than those at its edge. BHGs stayed active during on average $76.5 \%$ of daytime. In two urban colonies with the highest nest densities and highest level of light pollution birds slept less during the day than in other studied colonies (three rural and one urban) characterized by lower densities and light intensity after sunset near the colony. Knowledge of nocturnal behaviour is crucial to comprehend $24 \mathrm{~h}$ activity patterns of an organism, especially to understand flexibility of behaviour crucial for restoration, like sleep.
\end{abstract}

Keywords Nocturnal activity - Time-activity budget $\cdot$ Circadian rhythm $\cdot$ Colonial waterbird $\cdot$ Sleeping behaviour

Communicated by S. Bouwhuis.

Dariusz Jakubas

biodj@univ.gda.pl

1 Department of Biology and Animal Environment Landscaping, University of Technology and Life Sciences, ul. Mazowiecka 28, 85-084 Bydgoszcz, Poland

2 Department of Vertebrate Ecology and Zoology, Faculty of Biology, University of Gdańsk, ul. Wita Stwosza 59, 80-308 Gdańsk, Poland

3 Wudzyn, Poland 


\section{Zusammenfassung}

\section{Möwen schlafen bei Weitem nicht zu selben Zeiten—circadianer Aktivitätsrhythmus bei Lachmöwen während der Brutzeit}

Viele Wirbeltiere weisen eine Tagesaktivität auf, die durch den Helldunkel-Zyklus gesteuert wird. Einige koloniebildenden Wasservögel, darunter wenige Möwenarten, sind jedoch nicht nur tagsüber, sondern auch nachts aktiv. Ziel dieser Studie war es, den 24-Stunden-Aktiviätszyklus von Lachmöwen Chroicocephalus ridibundus (engl. Black-headed Gulls, BHG) mit Schwerpunkt auf dem Schlafverhalten zu untersuchen. Wir erwarteten, dass sich das 24-Stunden-Aktivitätsmuster zwischen Kolonien in verschiedenen Habitaten und innerhalb einer Kolonie zwischen Nestern im Zentrum und denen am Rand unterscheiden. Wir untersuchten das Verhalten anhand von 9.600 30-Sekunden-Videos von Kamerafallen, die in sechs Kolonien aufgestellt wurden, und anhand von Daten von zehn mit GPS-Loggern versehenen Individuen aus einer Kolonie, die während der Brutzeit aufzeichneten. BHGs blieben durchschnittlich 48,1\% einer Nacht aktiv und verbrachten diese Zeit hauptsächlich mit passiver und aktiver Nestverteidigung sowie Nestpflege. BHGs verbrachten tagsüber ähnlich viel Zeit mit diesen Aktivitäten. Individuen, die im Koloniezentrum brüteten, schliefen nachts länger als am Rande brütende Individuen. BHGs blieben durchschnittlich 76,5\% der Tageszeit aktiv. In den Kolonien mit den niedrigsten Nestdichten schliefen die Vögel tagsüber mehr als in Kolonien mit den höchsten Nestdichten. Die Länge des Schlafes während des Tages wurde durch die Lichtintensität nach Sonnenuntergang in der Nähe der Kolonie beeinflusst, und BHGs in städtischen Kolonien schliefen weniger als solche in ländlichen Kolonien. Die Kenntnis über das nächtliche Verhalten ist entscheidend für das Verständnis des 24-Stunden-Aktivitätsmuster eines Organismus, insbesondere wenn es um für die Erholung wichtige, flexible Verhaltenswiesen wie den Schlaf geht.

\section{Introduction}

Gulls, as many other groups of birds, are commonly considered active only during the day (Burger 1988; Yorio et al. 2005; Hayes and Hayward 2020). However, some colonial waterbirds including at least 20 species of gulls have been reported to be active also at night (Burger and Staine 1993; McNeil et al. 1992, 1993). Knowledge on nocturnal activity of gulls is poor and fragmentary, and considers mainly night foraging or feeding chicks, and copulations at night (e.g., Leck 1971; Underhill 1987; Tarburton 1991; Yorio et al. 2005), but not the entire spectrum of their activities at night. Among gulls, probably only the swallow-tailed gull Creagrus furcatus feeds exclusively at night (Harris 1970). Other gull species do it irregularly, and rather in favourable environmental conditions, as moonlight in cloudless nights or artificial light from trawlers, lighthouses and airports. It has been shown that insects lured by artificial lights are preyed by grey-headed gulls Chroicocephalus cirrocephalus (Underhill 1987) and silver gulls Chroicocephalus novaehollandiae (Tarburton 1991). Herring gull Larus argentatus and slaty-backed gull Larus schistisagus have been reported to hunt in moonlit nights for Leach's storm-petrels Oceanodroma leucorhoa (Harris 1974; Pierotti and Annett 1987, 1990; Tarburton 1991; Watanuki 1986), and western gulls Larus occidentalis for Cassin's auklets Ptychoramphus aleuticus (Nelson 1989). Ring-billed gull Larus delawarensis and red-legged kittiwake Rissa brevirostris in moonlight nights hunt for fish coming to the water surface (Leck 1971; Fetterolf 1979; Hunt et al. 1981a, b). Gray gull Leucophaeus modestus (Underhill 1987) and Pallas's gull Ichthyaetus ichthyaetus (Cramp and Simmons 1983) not only forage at night, but also feed chicks. Regular studies of other aspects of nocturnal activities in gulls, e.g. interactions with neighbours, synchronizing timing of sleep with activities of the closest neighbours in a colony (so-called collective waves of sleep-Beauchamp 2011; Evans et al. 2018), or full time budget, are rare.

The aim of our study was to investigate $24 \mathrm{~h}$ pattern of activity of the black-headed gull Chroicocephalus ridibun$d u s$ (hereafter BHG) during the period of incubation with special emphasis on nocturnal activity. In a pair, both male and female incubate eggs, swopping regularly at the nest (Cramp and Simmons 1983). During 3.5 weeks of long incubation (Harrison 1975), both partners actively defend their nesting territory against BHGs and other species breeding in their colony (Bukacińska and Bukaciński 1994; Indykiewicz and Minias 2019). In case of danger from predators, the pair jointly defend the colony, but often leave it temporarily (Indykiewicz 2015). During incubation, they forage mainly near the colony, depending on the colony size and environment (Jakubas et al. 2020). Some authors suggest exclusively diurnal activity of this species (Chandler 1983; Wikelski et al. 2006; Evans et al. 2018). However, one may expect that BHG is also active at night, as other gulls (Arcos and Oro 2002; Leopold et al. 2010). Here, we focused on sleep behaviour because severe sleep deprivation can reduce cognitive and physical performance in vertebrates (Rechtschaffen and Bergmann 2002; Shaw et al. 2002; Huber et al. 2004; Rattenborg et al. 2004; Snyder et al. 2013; but see Rattenborg 2017). Thus, one may expect that sleep deficits may 
require compensatory adjustments at the expense of other activities (Fuchs et al. 2006).

In this study, we investigated whether $24 \mathrm{~h}$ pattern of sleep behaviour in the studied colonial represents a flexible response to social or environmental factors (Lima 2005). We formulated the following hypotheses:

(1) individuals that sleep short at night compensate this nocturnal sleep deficiency during the day to secure restoration of organism and unbiased cognitive and physical performance (Rattenborg et al. 2004, 2009; Fuchs et al. 2006; Németh 2009; Covino and Cooney 2015);

(2) in the colonies with the highest nest densities, BHGs spend more time on defending nesting territories, nests and eggs, and in a consequence, they spend less time on other activities, including sleep, compared to individuals breeding in colonies with low densities of breeding pairs (Bukacińska and Bukaciński 1993; Besnard et al. 2006; Druzyaka et al. 2015; Indykiewicz and Minias 2019);

(3) in the colonies affected by light pollution at night, especially those located in urban areas, BHGs spend less time on nocturnal vigilance and sleep more compared to those in the colonies in rural areas less affected by this factor (Raap et al. 2017; Kempenaers et al. 2010; Steinmeyer et al. 2010; Russ et al. 2015);

(4) birds breeding at peripheries of colonies spend less time on sleep, both at day and night, compared to pairs breeding in the core centre of a colony, in response to stress of danger from potential predators (Velando and Freire 2001; Lima 2005; Minias 2014).

\section{Materials and methods}

\section{Study area}

We studied BHGs during the incubation period in six breeding colonies in N Poland in 2016-2019. All colonies were situated on islands in the lakes or rivers in farmland or urban areas. The colonies differed in the number and density of breeding pairs, the structure and diversity of vegetation covering an island, and the structure of surface around a water body. Three urban colonies (in Bydgoszcz town) were located 0.9-6.1 km apart. Two of them (BYD-SP and BYDPR) were surrounded by strongly developed areas, with factories, service buildings and railway. The third colony (BYD-LP) was situated in the recreational area near the northern border of the town, about $5 \mathrm{~km}$ away of its core centre. Three rural colonies were surrounded mostly by arable fields, meadows and forests (Fig. SM1, Table SM1, Supplementary Materials).

\section{Recording behaviour of black-headed gulls}

In all six studied colonies, behaviour of BHGs was recorded automatically with camera traps TV624M (BUSHNELL, USA) with No-Glow LEDs. They were installed at least $0.9 \mathrm{~m}$ away of the focal nest. To entirely eliminate the risk of nest abandonment by BHG, the camera traps in cryptic colours were additionally masked using vegetation.

Two to five camera traps at a time were set up in a colony, depending on its size and surface relief. Camera traps were located in the colony at the distance of a few or few tens of metres from each other in such a way that each of them recorded different 2-3 nests. This prevented simultaneous recording of birds representing the same group (e.g. nesting at the edge or in the centre of the colony). This camera setting eliminated any risk of simultaneous recording of birds from neighbouring groups, and thus avoiding recording the copied behaviour of neighbours, so-called "collective waves of sleep" (Beauchamp 2009, 2011, 2012).

Behaviour of BHG was recorded in all colonies between 21 April and 1 June (mid and late incubation period), during day and night. Because the time of sunrise and sunset changed over this period (sunrise-05:35 and 04:27, sunset-19:57 and 21:03, on 21 April and 1 June, respectively, according to the Central European Time) the length of days and nights also changed. On 21 April, the day length was about $14.5 \mathrm{~h}$ and the night was $9.5 \mathrm{~h}$, but on 1 April 16.5 and $7.5 \mathrm{~h}$, respectively.

We selected only the nests with three eggs (the full clutch), and where no more than 14 days had passed since the last eggs had been laid. Such approach eliminated any potentially harmful effect of the person setting the camera traps on abandoning the clutch at the last stage of chick hatching. All camera traps were programmed to record the view according to the same time schedule. In practice, they recorded $30 \mathrm{~s}$ of vision and sound in $30 \mathrm{~min}$ intervals, during six time intervals (T1-T6), considering natural variation of birds' activity during the day and night. At the first day of recording (21 April), the time intervals were: 5:30-7:00 (T1), 12:00-13:30 (T2), 18:30-20:00 (T3), 21:30-23:00 (T4), 00:00-1:30 (T5) and 3:00-4:30 (T6). In subsequent days, until 1 June, the time periods were adjusted to changing times of sunrise and sunset. In practice, this meant recording three movies in each time interval (T1-T6), thus 18 movies per $24 \mathrm{~h}$, for each nest within the scope of a camera trap. Usually two or three nests were located within the scope of recording by a camera trap, depending on the distance between the nests. Each nest was filmed only over one $24 \mathrm{~h}$ period. Each filmed nest was individually marked with a small marker $(30 \times 50 \mathrm{~mm})$ with the nest number, and its location was recorded on a map. This procedure ensured that birds from each nest were not filmed in subsequent days of study. Individuals in recorded nests were not individually 
marked, because our study was aimed to investigate the time budget of birds remaining in the colony, not to record activities of individuals.

We recorded a total of 11,680 movies. However, for final analysis, we qualified 9697 movies (Table SM2, Supplementary Materials), which recorded behaviour of 534 BHGs in full time schedule, i.e. 18 movies, three in each time interval T1-T6. Excluded movies were characterized by, insufficient quality caused for example by fog, rapid rainfall, camera falling etc.

\section{Analysed types of behaviour}

While determining the time budget of BHGs during egg incubation, we focused mainly on behaviour of birds that remained in the nest. We consider neither involvement of each individual in a pair with incubation of eggs nor their behaviour outside the breeding colony, as foraging or rest outside the island, bathing in water, etc.

Based on the collected documentation, we distinguished in BHGs the following types of behaviour:

- sleep (SLE) — the stage in which a bird had eyes closed and was sitting or standing, and laid bill under or on feathers of the back (back sleep), or lowered head and leaned its bill against breast (front sleep). Sporadic opening eyes (blinking) was treated as a natural element of sleep, as described by Amlaner and McFarland (1981) and Amlaner and Ball (1994);

- defence of nest and nesting territory-reaction of birds to appearance of predator, human intruder (gravel pit worker and swimmer/sunbather) or interspecific in a close proximity of the nest; we divided this type of behaviour into two subcategories: 1) active defence (ADE)—when BHG was involved in an aggressive interaction with one or several individuals, or when BHG remaining in the nests stretched its neck towards a neighbour or intruder and usually vocalized, 2) passive defence (PDE) — when the recorded individual stayed in the nest in sitting position with eyes opened, but without any elements of aggressive behaviour or any other activities (e.g. preening, fixing nest material or turning eggs);

- preening (PRE) - this behaviour included mainly cleaning feathers, fixing their structure and arranging them, and combing feathers to remove ectoparasites;

- nest maintenance (NEM) - fixing the structure of a nest and adding building material, usually found near the nest;

- common activities of a pair (COA) - e.g. bowing to greet each other, copulation, mutual grooming, swopping partners on a nest;

- other activities (OTA) - e.g. improving arrangement of eggs or turning them, preparations for flight and leaving the nest, stretching wing and leg on one side while standing;

The duration of these activities was determined during playing subsequent movies recorded by camera traps. This job was conducted in comfortable conditions by one person (JG).

\section{GPS-tracking}

To characterize $24 \mathrm{~h}$ pattern of BHGs flights during the incubation period, we used small PinPoint-10 GPS store-onboard loggers (1.3 g; Lotek Wireless Inc.), which recorded time and position. We deployed loggers on one member of a pair in 10 nests from the colony BYD-PR. We captured birds on nests during the second to fourth week of the incubation period using spring traps (ECOTONE) or loops made of nylon strings. We attached the tags to the central back feathers of each bird using two 3-4 mm-wide strips of tape code 4.965 (TESA Tape Inc.) crosswise-applied approximately at the midpoint of the centreline of the body. The logger weight (1.6 g, including attachment) was on average equivalent to $0.69 \%$ body mass of the captured individuals.

We set the loggers to collect data at 15 min intervals. After about $48 \mathrm{~h}$ from logger deployment, we tried to recapture birds and retrieve the loggers. We deployed 10 loggers and recaptured all birds successfully. In total, we analysed 36 trips from 10 individuals. In that for six individuals, we recorded locations both at the day and night from 10 to 26 May; four remaining individuals showed locations only in diurnal hours. To estimate influence of GPS-logger equipped individuals on their breeding performance, we compared hatching success in nests of equipped individuals $(N=10)$ and in control nests with not logger-burdened individuals $(N=151)$. We chose control nests with the same clutch size as in the nests of the logger-equipped birds, i.e. containing three eggs. We found that hatching success was similar in the nests with GPS-logger burdened one of the parents (93.3\%) and in the control nests (78.8\%; chi-squared test of independence, $\left.\chi^{2}=0.387, \mathrm{df}=1, p=0.534\right)$.

\section{Statistical analyses}

\section{Factors affecting relative duration of sleep behaviour}

To analyse proportion of time devoted to sleeping behaviour per recording unit, we firstly divided the duration of sleep by the recording time (30 s). As the distribution of the data on sleeping behaviour departed from normal and had bimodal distribution, we used beta regression. Since in beta regression, values should not include 0 and 1 and our data did, we used transformation $x=(x *(n-1)+0.5) / n$, where $\mathrm{n}$ was the 
sample size (Smithson and Verkuilen 2006), here the number of all analysed $30 \mathrm{~s}$ recordings $(N=9697)$.

To analyze factors affecting the relative duration of sleep, we used beta regression mixed model with colony, colony sector (central, peripheral), day/night, and their interactions as factorial predictors and nest identity as a random factor. We considered nests located in the $0-1.5 \mathrm{~m}$ wide zone adjacent to the water line (island edge) as peripheral; those located $>1.5 \mathrm{~m}$ from the water line as central.

As the observed individuals were not individually marked, we used nest identity, not bird identity as the random factor. As BHGs partners share incubation duties equally (Ytreberg 1956; Beer 1961), we assume that our results are not biased by overrepresentation/underrepresentation of one of the sexes.

We performed beta regression models in $\operatorname{glmm} T M B$ (Brooks et al. 2017), post hoc estimated marginal means tests in lsmeans (Length 2016) packages in R software (R Core Team 2019).

\section{Differences in relative duration of each behaviour}

To compare relative duration of each type of behaviour between the night and day, and between the colonies, we used $G$ test for independence in rcompanion package (Fox and Weisberg 2011) in R software. In some analyses, we considered all types of behaviour as $100 \%$ of time, in other analyses all types of behaviour excluding sleep were $100 \%$. We applied the second approach because BHGs spent most time on sleeping, which masked the importance of other less frequent behaviours. To compare daily distributions of the relative duration of each type of behaviour between the colonies, we used Anderson-Darling $k$ sample test in kSamples package in R software (R Core Team 2019). We analysed values averaged for each time interval (T1-T6).

\section{Relationship between sleep duration and various external factors}

To investigate relationships between relative sleep duration in each colony with the colony size, colony density and intensity of nocturnal light pollution, we used Pearson correlations. We performed separate analyses for diurnal and nocturnal sleep behaviour. To check whether denser colonies are not located in the areas with higher light pollution levels (e.g. because of closer location to the urbanized areas), we also investigated relationship between the nest density and light pollution.

\section{Flights of GPS-tracked individuals}

We analysed the following characteristics of BHGs trips based on geographical positions recorded by the GPS loggers:

(1) maximum range of flights $(\mathrm{km})$ - the distance from the colony to the distal point reached on each foraging trip;

(2) total distance covered $(\mathrm{km})$ - the sum of distances between consecutive GPS positions along each individual's track;

(3) total trip duration (min) - the time between departure and return to the colony.

We defined as a trip flights with at least three positions recorded in a minimum distance of $1 \mathrm{~km}$ away of the colony.

To compare the listed characteristic of trips between day and night, we used mixed gamma regression model (maximum range of flights as it departed from the normal distribution) or linear mixed models (total distance covered, total trip duration) with day/night as a factorial predictor and bird identity as a random factor.

We performed mixed gamma regression and linear mixed model in lme4 and lmerTest (Kuznetsova et al. 2017) packages in R software (R Core Team 2019).

In all statistical analyses, we set the alpha level at 0.05 . We mapped GPS-tracking data, extracted data from the CORINE model and produced all figures with maps using ArcMap/ArcGIS 10.3.1 (Redlands, CA: Environmental Systems Research Institute).

\section{Results}

We found that BHG were active not only at day, but also in late evening and at night. This was documented by recordings from camera traps set near the nests in all studied

Table 1 Effects of studied predictors on the relative length of sleep of black-headed gulls during egg incubation

\begin{tabular}{lrlll}
\hline Predictors & \multicolumn{1}{c}{$\chi^{2}$} & df & $\operatorname{Pr}\left(\chi^{2}\right)$ & $p$ \\
\hline Colony & 50.526 & 5 & $1.082 \mathrm{e}-09$ & 0.001 \\
Day/night & 645.897 & 1 & $<2.2 \mathrm{e}-16$ & 0.001 \\
Colony sector & 15.427 & 1 & $8.575 \mathrm{e}-05$ & 0.001 \\
Colony $\times$ day/night & 225.444 & 5 & $<2.2 \mathrm{e}-16$ & 0.001 \\
Colony $\times$ colony sector & 40.901 & 5 & $9.826 \mathrm{e}-08$ & 0.001 \\
Day/night $\times$ colony sector & 26.524 & 1 & $2.603 \mathrm{e}-07$ & 0.001 \\
Colony $\times$ day/night $\times$ colony & 29.490 & 5 & $1.858 \mathrm{e}-05$ & 0.001 \\
$\quad$ & & & & \\
\hline
\end{tabular}

Beta regression mixed model 
Table 2 Proportion of time (\%) allocated to sleep by black-headed gulls of diurnal, night, diurnal and night combined in $30 \mathrm{~s}$ recordings in the studied breeding colonies during egg incubation

\begin{tabular}{llllll}
\hline Colony (code) & \multicolumn{4}{l}{ Mean proportion $(\%)$ of time allocated to sleep behavior in 30 s recording } \\
\cline { 2 - 6 } & DI. diurnal $(n)$ & NO. nocturnal $(n)$ & $\begin{array}{l}\text { DI. vs NO. } \\
\text { comparison } \\
p \text { value }\end{array}$ & $\begin{array}{l}\text { DINO-DI. and } \\
\text { NO. combined }(N)\end{array}$ & $\begin{array}{l}\text { DINO } \\
\text { Significant contrasts }\end{array}$ \\
\hline Bydgoszcz-Konna (BYD-LP) & $23.2(1058)$ & $49.9(701)$ & $<0.001$ & $33.8(1759)$ & $\mathrm{a}^{* *}, \mathrm{~b}^{* *}$ \\
Bydgoszcz-Stary Port (BYD-SP) & $12.4(443)$ & $55.5(570)$ & $<0.001$ & $36.6(1013)$ & $\mathrm{c}^{* *}$ \\
Bydgoszcz-Przemysłowa (BYD-PR) & $15.2(430)$ & $45.4(715)$ & $<0.001$ & $34.0(1145)$ & $\mathrm{d}^{* * *}, \mathrm{e}^{*}$ \\
Koronowo (KOR) & $24.2(1499)$ & $59.1(1281)$ & $<0.001$ & $40.3(2780)$ & $\mathrm{a}^{* *}, \mathrm{c}^{* *}, \mathrm{~d}^{* * *}, \mathrm{f}^{* * *}$ \\
Kusowo (KUS) & $24.9(180)$ & $52.5(79)$ & 0.001 & $33.3(259)$ & $\mathrm{e}^{*}, \mathrm{~g}^{* *}$ \\
Skoki Duże (SKO) & $28.7(1469)$ & $33.8(1272)$ & 1.0 & $31.1(2741)$ & $\mathrm{b}^{* *}, \mathrm{f}^{* * *}, \mathrm{~g}^{* *}$ \\
\hline
\end{tabular}

$N$-sample size, i.e. number of $30 \mathrm{~s}$ recordings. Significance levels: $* p<0.05, * * p<0.01, * * * p<0.001$. Values: $a 0.006, b 0.008, c 0.004$, $d<0.001, e 0.016, f<0.001, g 0.003$

${ }^{\text {h}}$ Beta regression, post-hoc estimated marginal means test

${ }^{i}$ Significant inter-colony contrasts, beta regression, post-hoc estimated marginal means test

colonies and the data recorded by GPS-tracked individuals from one colony (Fig. SM2, Supplementary Materials).

\section{Factors affecting relative duration of sleep behaviour}

We found that BHG partners that remained in nests during incubation of eggs spent on sleep $48.1 \pm 43.3 \%($ mean \pm SD) of $30 \mathrm{~s}$ nocturnal recordings, and $23.5 \pm 35.3 \%$ of $30 \mathrm{~s}$ diurnal recordings in each colony. This means that extrapolated time of sleep at night in these birds oscillated on average between 2.87 and $5.02 \mathrm{~h}$ (172-301 min). BHGs sleep over $31.1-40.3 \%$ of $30 \mathrm{~s}$ recordings depending on a colony. Beta regression model revealed that the relative duration of sleep during the incubation period was affected significantly by all studied predictors, i.e. colony (1-6), the part of $24 \mathrm{~h}$ (day/ night), location of a nest in the colony (centre/peripheries) and interactions between these factors (Table 1). The noted inter-colony differences were significant (Table 1) with the highest value at Koronowo and the lowest one at Skoki Duże (Table 2). Regarding day/night differences (Table 1) BHG slept longer at night (mean \pm SD: $48.0 \pm 43.3 \%$ of $30 \mathrm{~s}$ recording) than during the day $(23.5 \pm 35.3 \%)$.

Location of nests within a colony had a significant effect on the relative length of birds' sleep (Table 1) with birds nesting in the centre sleeping longer (mean \pm SD: $37.2 \pm 41.9 \%$ of $30 \mathrm{~s}$ recording) than in the edge $(32.7 \pm 40.1 \%)$.

We found a significant interaction colony $\times$ day/night (Table 1). Post hoc tests revealed that in all colonies, except of Skoki Duże, duration of sleep did not differ between night and day (Table 2).

We found a significant interaction colony sector $\times$ day/ night (Table 1). At night, BHGs that located their nests in the core centre of the island slept significantly longer (mean \pm SD $51.3 \pm 43.3 \%)$ than those that had nests at the edge of a colony ( $43.8 \pm 42.8 \%$; post hoc test, $p=0.001)$. During the day birds nesting at the edge only tended to spend a higher proportion of time to sleep $(23.9 \pm 35.7 \%)$ compared to individuals from the edge $(23.1 \pm 34.8 \%$; post hoc test, $p=0.069$ ).

We also found a significant interaction colony sector $x$ day/night $\times$ colony (Table 1 ). Post-hoc tests revealed that generally the length of BHGs sleep during the day did not depend on nest location within the colony (post-hoc test, $p=1.0$ ) except for the colony at Kusowo, where birds slept longer at the peripheries, contrary to our expectations (Fig. 1). At night, only in two colonies, BydgoszczPrzemysłowa and Skoki Duże, birds at peripheries slept significantly shorter than these in the centre of the colony (Fig. 1). In other colonies, relative duration of sleep behaviour was similar at the edge and in the centre if the colony (post hoc test, $p=1.0$ ).

Analysis of daily distribution of sleeping behaviour of incubating individuals revealed that the proportion of time allocated to this behaviour was highest in the evening, moderate in early afternoon and lowest in the morning (Fig. 2). Moreover, we found that the distribution of sleep periods in subsequent time intervals during $24 \mathrm{~h}$ did not differ between the colonies (Anderson-Darling test $\mathrm{AD}=4.092, p=0.694$ ). The location of a BHG nest in the centre or at the periphery of the colony also had no effect on $24 \mathrm{~h}$ distribution of sleep (Anderson-Darling test, $\mathrm{AD}=0.549 ; p=0.769$ ).

\section{Other activities of incubating individuals}

Sleeping by BHGs on average over $48.4 \%$ of night means that they were active throughout the remaining part of a night. They spent most of this active time on passive and 


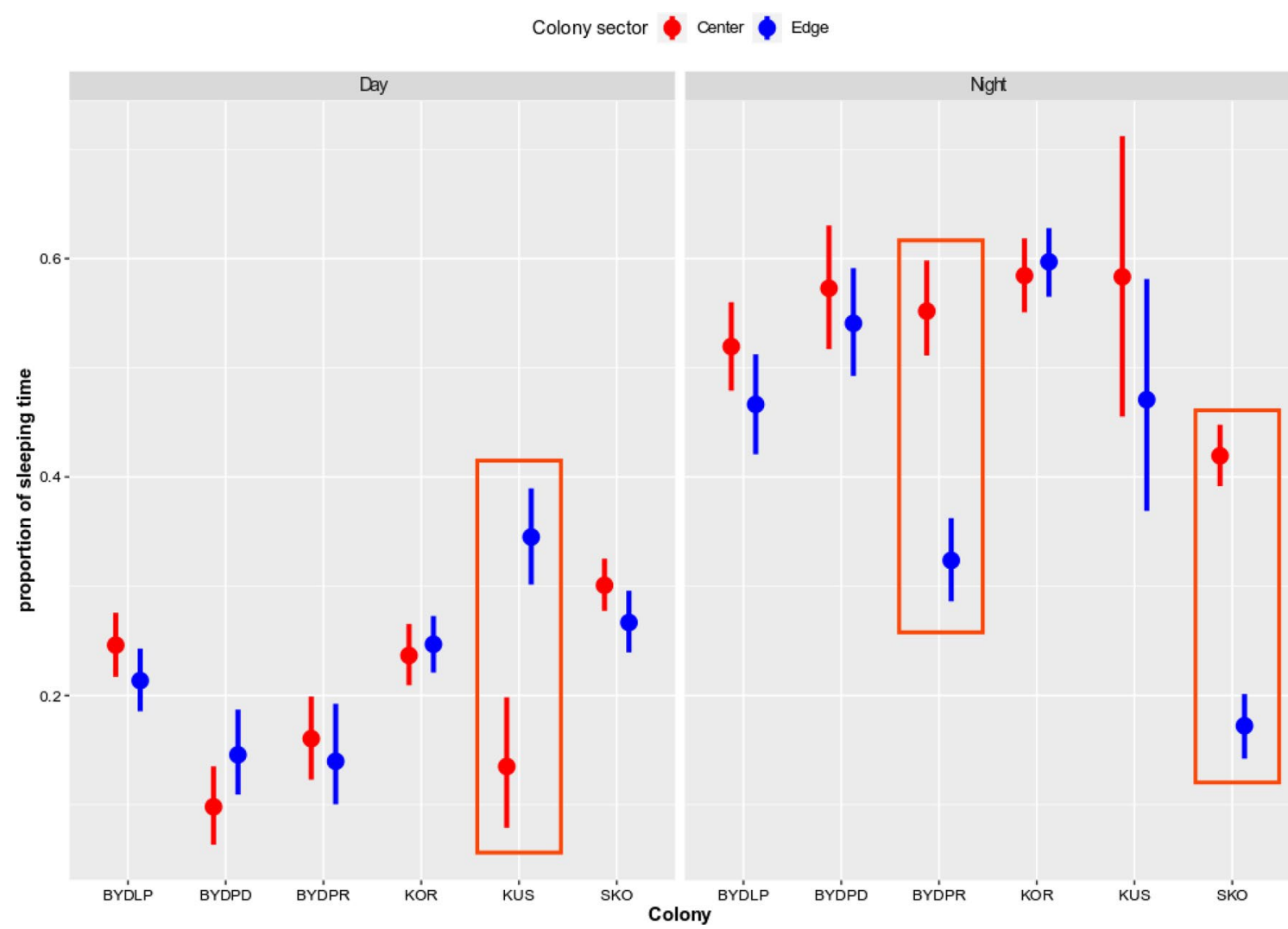

Fig. 1 Proportion of time allocated to sleep in day and at night by black-headed gulls in relation to their nest location within a colony (centre vs edge). Red rectangles indicate significant differences between colony sectors (beta regression, post hoc test, $p<0.007$ ). Colony codes see Table 2 and Table SM1 in Supplementary Materials

\section{Differences between nocturnal and diurnal flights of GPS-tracked individuals}

Analyses of GPS-tracking data revealed that after leaving the colony at night BHG crossed much shorter distance (total distance of flight) than at the day (linear mixed model, estimate $=-0.731, \mathrm{df}=30.295, t=-2.310, p=0.030$; Fig. 4a). We also found that the maximal range of nocturnal flights of BHGs were considerably shorter than daily flights (gamma regression, estimate $=-0.892, \mathrm{df}=32, t=-3.629$, $p=0.0003$; Fig. 4b), and that BHGs remained outside the breeding colony much longer at night than during the day (linear mixed model: estimate $=0.826, \mathrm{df}=34, t=5.450$, $p<0.001$; Fig. 4c).

\section{Relationship between nocturnal and diurnal sleeping and various factors}

We found that the duration of BHG's sleep during the day was significantly related to the density of nests in the colony (Pearson correlation, $r=-0.958, t=-6.726, \mathrm{df}=4$, $p=0.002$; Fig. SM3, Supplementary Materials). In colonies 

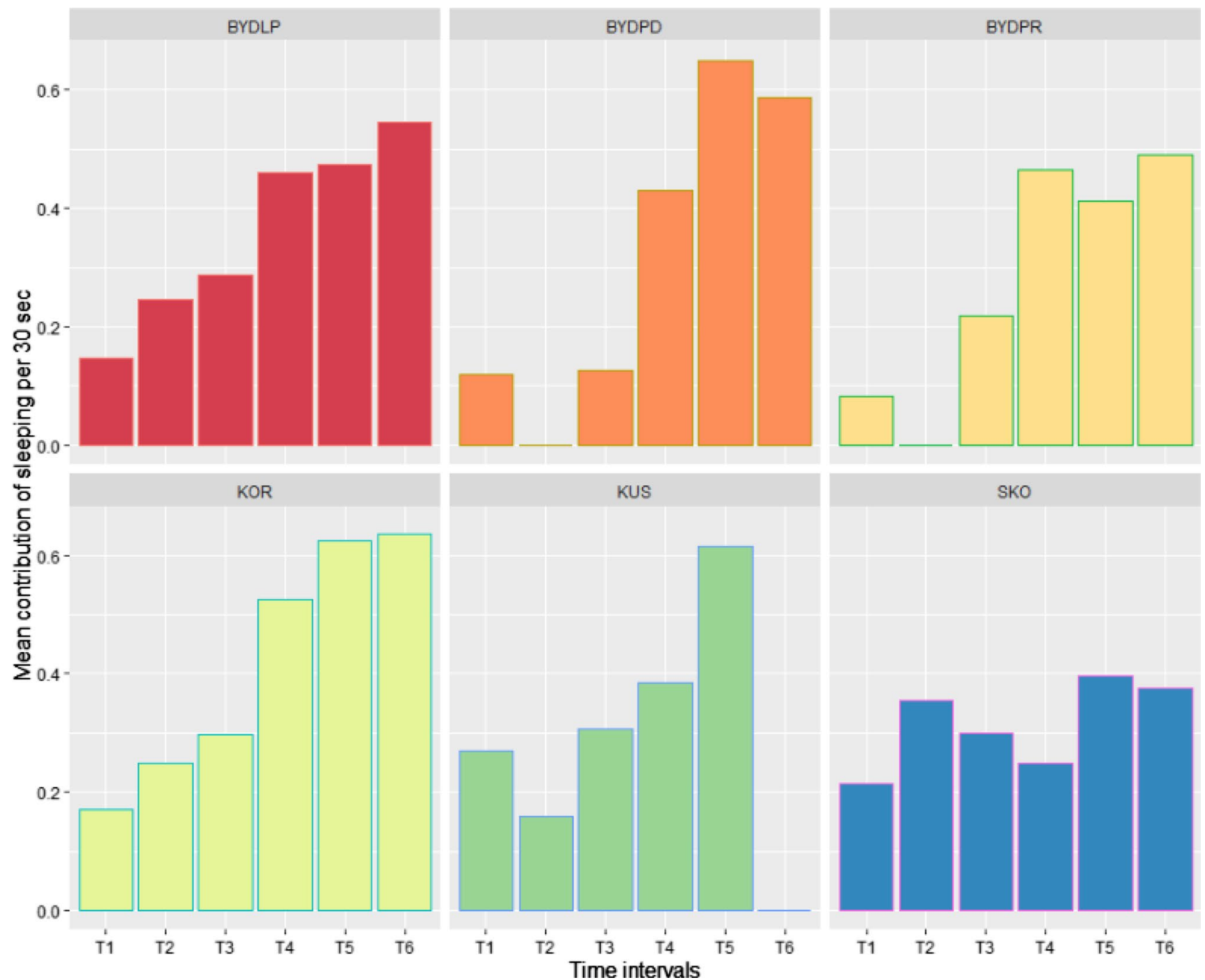

Fig. 2 Mean contribution of the sleeping behaviour of black-headed gulls per recording in particular time intervals over $24 \mathrm{~h}$ in each colony during egg incubation. Colony codes see Table SM1 in Sup-

plementary Materials. Time intervals: 5:30-7:00 (T1), 12:00-13:30 (T2), 18:30-20:00 (T3), 21:30-23:00 (T4), 00:00-1:30 (T5) and 3:00-4:30 (T6)

where the density of nests was the smallest birds slept over proportionally larger part of the day compared to birds breeding in the highest densities. However, we found no effect of nest densities on the length of BHGs sleep at night $(r=0.170, t=0.345, \mathrm{df}=4, p=0.747)$.

Moreover, we found that the amount of time allocated by BHGs to sleep during the day was significantly related to light pollution intensity around the colony after dusk (Pearson correlation, $r=-0.929, \mathrm{t}=-5.031, \mathrm{df}=4, p=0.007$; Fig. SM4, Supplementary Materials). In colonies where the light pollution intensity was the smallest birds slept over proportionally larger part of the day compared to birds breeding in the highest densities. However, we found no effect of light pollution intensity on the length sleep at night $(r=0.037$, $t=0.074, \mathrm{df}=4, p=0.945)$. We also found that the density

of nests in the colony was positively correlated with light pollution intensity around the colony after dusk (Pearson correlation, $r=0.925, t=4.874, \mathrm{df}=4, p=0.008)$.

\section{Discussion}

BHG is commonly considered a species of exclusively diurnal activity (Chandler 1983; Wikelski et al. 2006; Evans et al. 2018), but literature provides a few mentions their incidental nocturnal activity (Coward 1916; Beer 1962; Kruuk 1964; Hailman 1966). Our studies showed that at least during incubation of eggs, BHGs are active not only during the day, but are also regularly active after dusk, i.e. in late evening and night hours. This result is intriguing given the 


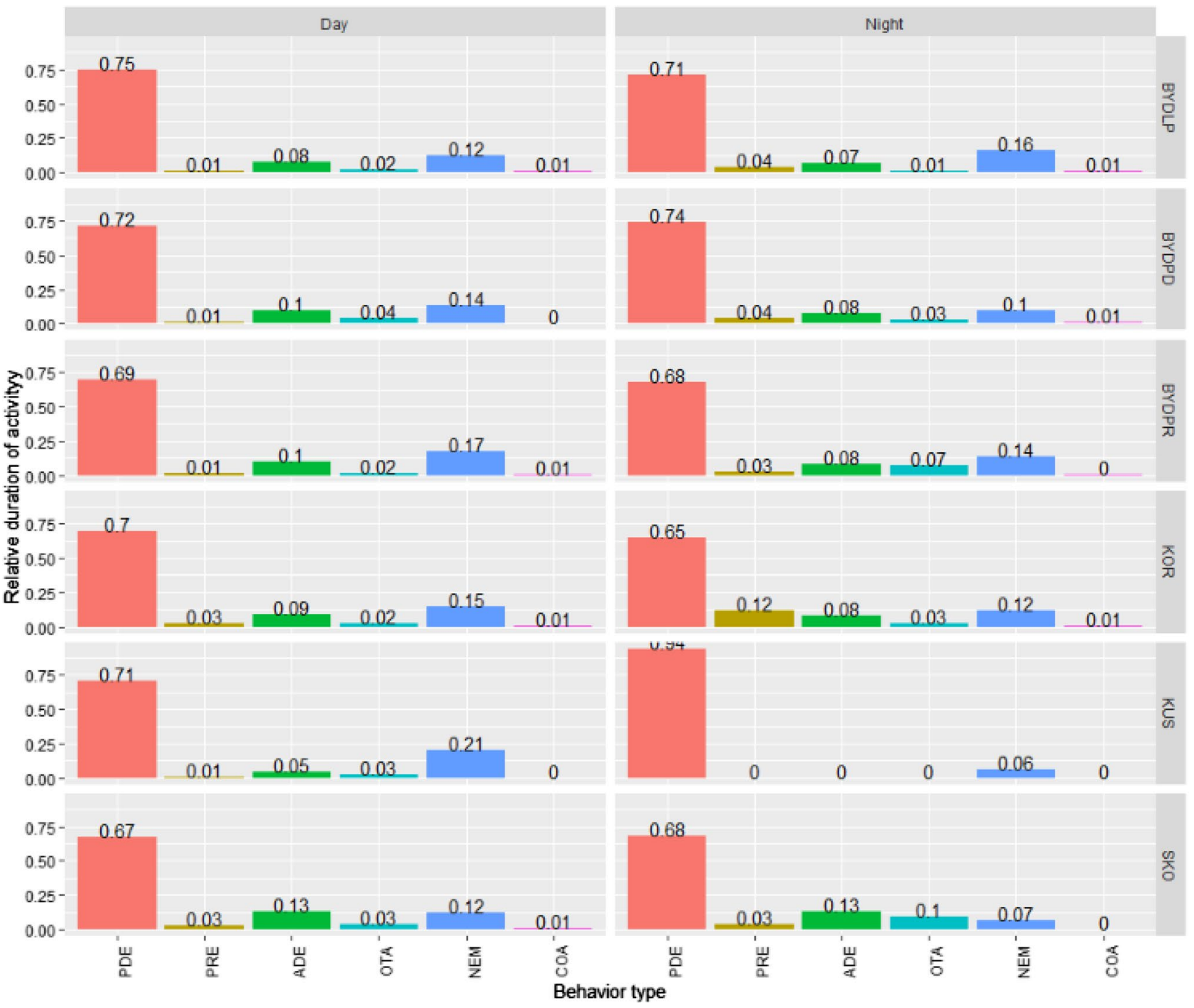

Fig. 3 Relative duration of diurnal and nocturnal activities (other than sleeping) of black-headed gulls during egg incubation. Behaviour codes: $P D E$ passive defence, $P R E$ preening, $A D E$ active defence,

fact that concentration of melatonin during $24 \mathrm{~h}$ in BHGs is relatively low compared to other gull species; it may enable BHGs to fall asleep easily at any time of day or night (and possibly guarantees their efficient restoration), and allowing to be ready for defend the nest with eggs or chicks during 24 h (Meyer and Millam 1991; John et al. 1993; Jessop et al. 2002; Wikelski et al. 2006).

Moreover, we found that the distribution of sleep periods and activity of BHGs in distinguished time periods (T1-T6) was similar in studied colonies, but their total sleep time at night differed between the colonies. These differences may be explained by various ecological and social conditions in colonies, naturally influencing birds' behaviour (e.g.
OTA other activities, NEM nest maintenance, SLE sleep, COA common activities of a pair. Colony codes see Table 2 and Table SM1 in Supplementary Materials

predation pressure, nest density, vegetation height and type and visibility of the surrounding area, time budget).

One of the studied factors, which might determine the length of sleep in $\mathrm{BHG}$, was nest location. BHGs breeding in the centre of a colony slept longer at night than those that had nests at the edge of the island, as we expected. Birds at the peripheries of a colony were probably exposed to higher stress caused by potential danger from predators, and thus increased frequency or duration of vigilance periods, at the cost of rest and possibly restoration. This scenario seems the more probable as earlier studies showed that many bird species sleep less or shallower under predator danger (Lendrem 1983, 1984; Gauthier-Clerc et al. 1998, 2000, 2002; Dominguez 2003; Lima 2005; Diehl et al. 2020). Moreover, 

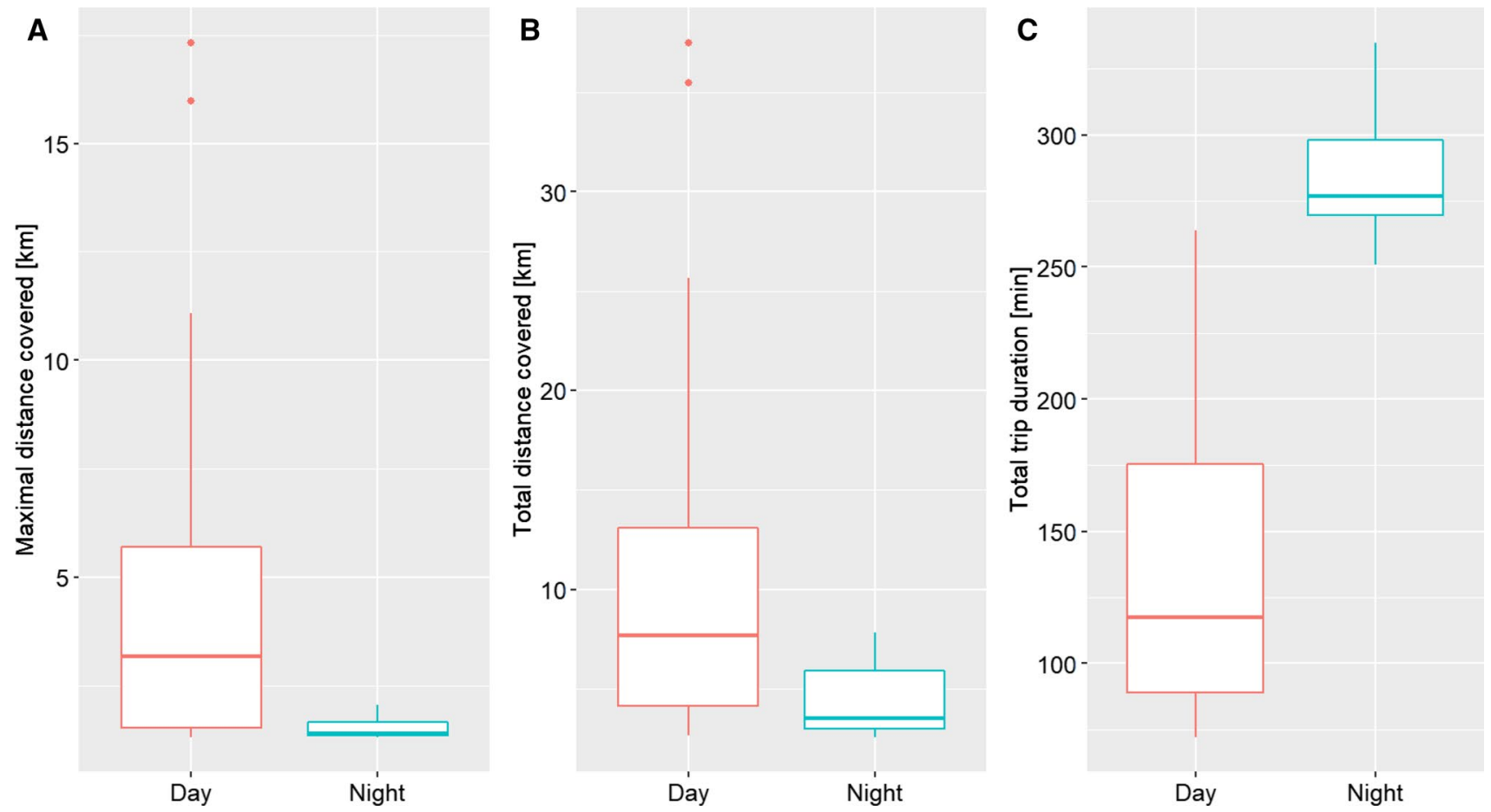

Fig. 4 Characteristics of nocturnal and diurnal flights of GPS-tracked black-headed gulls breeding in the colony at Bydgoszcz (BYD-PR) during incubation period: A maximum range of flights $(\mathrm{km}), \mathbf{B}$ total distance covered $(\mathrm{km}), \mathbf{C}$ total trip duration $(\mathrm{min})$. Boxplots show the

median (band inside the box), the first (25\%) and third (75\%) quartile (box), the lowest and the highest values within 1.5 interquartile range (whiskers) and outliers (dots)

the core of the colony usually offers the birds better protection against predators than peripheries. Colony centres are more difficult to access for predators, and higher density of breeding pairs in the centre enables more efficient detection of and deterring predators than at its edge (Davis and McCaffrey 1986; Becker 1995; Yorio and Quintana 1997; Velando and Freire 2001; Beauchamp 2009, 2012; Minias 2014). Because BHGs from the peripheries slept shorter at night, we expected they would compensate the night sleep deficit during the day and regenerate in this way. We thought this would be possible because during the day vigilance of each individual in a colony can be partly replaced with group vigilance, according to the rule "the neighbour sleeps, so do I" (Beauchamp 2009, 2011; Beauchamp et al. 2012; Evans et al. 2018), and such mechanism might promote more frequent and longer naps. However, contrary to our expectations, birds from colony's edge did not compensate for their deficit of night sleep during the day. It is surprising, because long sleep deprivation leads to negative physiological consequences (Huber et al. 2004; Rattenborg et al. 2004; Snyder et al. 2013). Thus, it might be expected that BHGs that nest at the colony's edge, despite shorter sleep at night, sleep sufficiently long or deep at the day. Perhaps only at the next lifestage, when energy expenses of adults are much larger than during incubation (they have to satisfy their own and chicks' energy demands), the accumulated deficit of nocturnal sleep in individuals from colony's edge might be compensated with longer diurnal sleep.

Probably, BHGs have a specific adaptation that enables them to shorten sleep at night without any loss of organisms' functions during the day, analogously as in male pectoral sandpipers Calidris melanotos, which shorten sleep during competitive displays to increase breeding success and compensate for it with better quality sleep (Lesku et al. 2012). Another explanation for a lack of compensation for nocturnal sleep deficit might be unihemispheric sleep, detected in some avian species (Rattenborg 2006; Rattenborg et al. 2019). Possibly, BHGs also perform such sleep mode. However, neither the literature nor recordings from our camera traps provided any convincing evidence of unihemispheric sleep in BHGs. Our camera trap (set almost opposite to a sleeping bird or behind it) movies ( $N=19$ recordings) have shown that only in $32 \%$ cases the bird certainly had one eye open and the other one shut, and in about $42 \%$ cases the bird had both eyes shut. Thus, we cannot state definitively that BHGs exhibited unihemispheric sleep in the colonies we studied. However, using such sleep by BHGs would likely enable full restoration of their organisms, as in e.g. great frigatebirds Fregata minor (Rattenborg et al. 2019); but see Rattenborg (2017) speculating that avian species may not 
require restoration after sleep deprivation at the expected extent and compared to mammals.

Our studies also revealed an interesting relationship between the intensity of light after dark around the colony and BHGs' sleep during the day. Individuals breeding in colonies that were more illuminated at night (which were also characterized by a higher nest density) slept significantly shorter during the day than in darker colonies. Given the fact that light intensity at night had no effect on their sleep length at night, and that the nest density in the colony was positively correlated with light pollution intensity around the colony after dusk, it seems that effect of nest density was more important driver of diurnal sleep duration compared to night light pollution. Dense colonies may attract predators increasing birds' vigilance in fear of predator's attack, at the cost of duration and quality of birds' total sleep [including deep sleep (back sleep) and rest sleep (front sleep)]. Likely, birds in dense colonies more often interrupted sleep to observe neighbourhood, which may impede efficient restoration of their organisms (Raap et al. 2017). More studies are needed to fully comprehend link between light intensity, nest density and sleep duration. Those studies should include direct measurement of light level (it can be masked by high cloudiness, lush vegetation) and some important covariates as noise level, human disturbance level, predatory pressure.

We found that some GPS-tracked individuals left the breeding colony for the whole or a part of the nights. It confirms the previous observations in gulls; their staying outside the colony at night, especially at the first phase of settling on an island (Hébert and McNeil 1999), has been interpreted as anti-predator behaviour (Kruuk 1964; Mougeot and Bretagnolle 2000; Nisbet 1999; Diehl et al. 2020). Apart from this, some seabirds, as black-vented shearwaters or ring-billed gulls, during bright moonlight nights reduce their activity in a colony and even leave it to avoid a predator's attack, as compared to dark nights (Hébert and McNeil 1999; Keitt et al. 2004). Thus, spending the night during egg incubation on water and roofs of building by some studied BGHs individuals may be interpreted in context of seeking resting place safer from predators compared to the colony.

We are aware of some limitations of our study. We based our study on video recorded material with restricted camera view, thus we cannot say if the partner of the filmed individual is not sleeping just outside the camera frame. We did not marked individually birds so we are not sure which individuals from the pair was present in the frame. However, considering an equal contribution of both partners in incubation duties (Ytreberg 1956; Beer 1961), we assumed that there was no female or male bias in the analysed material. Given the lateral position of the eyes on the head, it is rarely possible to see both eyes of a bird with a single camera frame. Thus, we cannot excluded that we might not see some episodes of the unihemispheric sleep, especially when only one side of bird was visible in the frame. We are aware that behaviour of the GPS-logger equipped individuals may be directly affected via expending extra energy countering both the additional mass and the increased drag, and decreasing some aspects of their performance, such as speed (Elliott et al. 2007; Vandenabeele et al. 2012). This bias might have affected the behaviour of the studied birds. We cannot exclude that birds in the first day after GPS-logger deployment behaved a little bit different than in the next day. Given small sample size we analysed data from all recorded days combined. We believe that the small size of the logger used $(0.69 \%$ body mass of the captured individuals) should not affect birds' behaviour considerably. Moreover, we found that the hatching success in nests in GPS-logger equipped individuals was similar to the control group (see Materials and methods).

Nevertheless, our results represent the first systematic study on sleep in black-headed gulls and filled evident gap in knowledge about nocturnal behaviour of the studied species. More studies including hemispheric sleep is needed to fully comprehend sleeping behaviour of gulls.

In conclusion, we found that during the incubation period, BHGs were active at night (contrary to standard belief) and their activity can vary with colony density, location of nest site and lighting around the colony. Knowledge of the nocturnal behaviour of an organism is crucial to fully comprehend its $24 \mathrm{~h}$ activity patterns, especially to understand daily flexibility of behaviour types crucial for restoration, like sleep.

Supplementary Information The online version contains supplementary material available at https://doi.org/10.1007/s10336-021-01896-8.

Acknowledgements We are thankful to colleagues from the Student's Zoological Science Club at the University of Science and Technology in Bydgoszcz who helped in the field work, especially to Aleksandra Kowalczyk and Malwina Pater. We are grateful to the Director of the Wdecki Landscape Park for a non-commercial lending of camera traps. We thank anonymous reviewers for constructive comments on the earlier draft of the manuscript.

Author contributions PI developed the concept of the study, collected data in the field, and drafted the manuscript, DJ performed statistical analyses, analysed GPS data and drafted the manuscript, JG analysed movies recorded by camera traps and collected data in the field. All authors read and approved the final manuscript.

Funding GPS-tracking was supported by the grant from National Science Centre (NCN), Poland, No. 2015/19/B/NZ8/01981.

Availability of data and material The datasets generated during and analysed during the current study are available from the corresponding author upon reasonable request.

\section{Declarations}

Conflict of interest The authors declare no conflicts of interests. 
Ethics approval GPS-tracking of birds was conducted with the permission of Local Bioethical Commission for Animal Welfare in Łódź and Regional Environmental Protection Directorates in Bydgoszcz (Poland).

Open Access This article is licensed under a Creative Commons Attribution 4.0 International License, which permits use, sharing, adaptation, distribution and reproduction in any medium or format, as long as you give appropriate credit to the original author(s) and the source, provide a link to the Creative Commons licence, and indicate if changes were made. The images or other third party material in this article are included in the article's Creative Commons licence, unless indicated otherwise in a credit line to the material. If material is not included in the article's Creative Commons licence and your intended use is not permitted by statutory regulation or exceeds the permitted use, you will need to obtain permission directly from the copyright holder. To view a copy of this licence, visit http://creativecommons.org/licenses/by/4.0/.

\section{References}

Amlaner CJ, Ball NJ (1994) Avian Sleep. In: Kryger MH, Roth T, Dement WC (eds) Principles and practice of sleep medicine. WB Saunders Company A Division of Harcourt Brace \& Company, Philadelphia, pp 81-93. https://doi.org/10.1002/ppul.1950080117

Amlaner CJr, McFarland DJ, (1981) Sleep in the Herring Gull (Larus argentatus). Anim Behav 29:551-556. https://doi.org/10.1016/ S0003-3472(81)80118-2

Arcos JM, Oro D (2002) Significance of nocturnal purse seine fisheries for seabirds: a case study off the Ebro Delta (NW Mediterranean). Mar Biol 141:277-286. https://doi.org/10.1007/ s00227-002-0828-3

Beauchamp G (2009) Sleeping gulls monitor the vigilance behaviour of their neighbours. Biol Lett 5:9-11. https://doi.org/10.1098/rsbl. 2008.0490

Beauchamp G (2011) Collective waves of sleep in gulls (Larus spp.). Ethology 117:326-331. https://doi.org/10.1111/j.1439-0310.2011. 01875.x

Beauchamp G, Alexander P, Jovani R (2012) Consistent waves of collective vigilance in groups using public information about predation risk. Behav Ecol 23:368-374. https://doi.org/10.1093/beheco/ arr194

Becker PH (1995) Effects of coloniality on gull predation on Common Tern (Sterna hirundo) chicks. Colon Waterbirds 18:11-22. https:// www.jstor.org/stable/1521394?seq=1

Beer CG (1961) Incubation and nest building behaviour of Blackheaded Gulls. I: incubation behaviour in the incubation period. Behaviour 18(1-2):62-105

Beer CG (1962) Incubation and nest-building behaviour of Blackheaded Gulls II: incubation behaviour in the laying period. Behaviour 19:283-304. https://www.jstor.org/stable/4533019?seq=1

Besnard A, Sadoul N, Lebreton J-D (2006) First quantitative comparison of aggression between crèching and non-crèching Larid species. Waterbirds 29:481-488. https://doi.org/10.1675/15244695(2006)29[481:FQCOAB]2.0.CO;2

Brooks ME, Kristensen K, van Benthem KJ, Magnusson A, Berg CW, Nielsen A, Skaug HJ, Maechler M, Bolker BM (2017) glmmTMB Balances Speed and Flexibility Among Packages for Zero-inflated Generalized Linear Mixed Modeling. $R$ J 9(2):378-400. https:// journal.r-project.org/archive/2017/RJ-2017-066/index.html

Bukacińska M, Bukaciński D (1993) The Effect of habitat structure and density of nests on territory size and territorial behaviour in the
Black-headed Gull (Larus ridibundus L.). Ethology 94:306-316. https://doi.org/10.1111/j.1439-0310.1993.tb00447.x

Bukacińska M, Bukaciński D (1994) Seasonal and diurnal changes in aggression and territory size in the black headed gull (Larus ridibundus) on the islands of the middle reaches of the Vistula river. Ethology 97:329-339 https://onlinelibrary.wiley.com/doi/ epdf/, https://doi.org/10.1111/j.1439-0310.1994.tb01051.x

Burger J, (1988) Foraging behavior in gulls: Differences in method, prey and habitat. Col Waterbirds 11:9-23. https://www.jstor.org/ stable/1521165

Burger J, Staine KJ (1993) Nocturnal behavior of gulls in coastal New Jersey. Estuaries 16:809-814. https://doi.org/10.2307/1352439

Chandler RJ (1983) Feeding-Behavior of Black-Headed Gull Brit Birds 76:85-87

Covino KM, Cooney B (2015) Daytime sleeping behavior observed in a Black and-white Warbler during spring stopover. Anim Migr 2:44-46. https://doi.org/10.1515/ami-2015-0001

Coward TA (1916) A change in the habits of the Black-headed Gull. Mem Proc Manchester Lit Phil Soc 60:1-6

Cramp S, Simmons KEL (1983) Handbook of the birds of Europe, the Middle East and North Africa: the Birds of the Western Palearctic, vol 3. Oxford University Press, Oxford, Waders to Gulls

Davis LS, McCaffrey FT (1986) Survival analysis of eggs and chicks of Adélie Penguins (Pygoscelis adeliae). Auk 103:379-388. https:// doi.org/10.1093/auk/103.2.379

Diehl J, Korpi ZO, Oswald SA, Curtis PD, Arnold JM (2020) Nocturnal sleep behavior and vigilance of incubating Common Terns (Sterna hirundo) at two inland breeding colonies. Waterbirds 43(1):28-35. https://doi.org/10.1675/063.043.0103

Dominguez J (2003) Sleeping and vigilance in black-tailed godwit. J Ethol 21:57-60. https://doi.org/10.1007/s10164-002-0074-7

Druzyaka AV, Minina MA, Chasovskikh ZV (2015) The early development of aggressive behavior and rapid growth of chicks in the Black-headed gull (Larus ridibundus) in conditions of diffused nesting. Biol B 42(9):808-820. https://doi.org/10.1134/S1062 359015090034

Elliott KH, Davoren GK, Gaston AJ (2007) The influence of buoyancy, and drag on the dive behaviour of an Arctic seabird, the Thickbilled Murre. Can J Zool 85:352-361

Evans MHR, Lihou KL, Rands SA (2018) Black-headed gulls synchronise their activity with their nearest neighbours. Sci Rep 8:9978. https://doi.org/10.1038/s41598-018-28378-x

Fetterolf PM (1979) Nocturnal behaviour of Ring-billed Gulls during the early incubation period. Can J Zool 57:1190-1195. https:// doi.org/10.1139/z79-151

Fox J, Weisberg S (2011) An R Companion to Applied Regression. Second. ed. Sage, Thou- sand Oaks CA. https://doi.org/10.1080/ 10543406.2012.635980

Fuchs T, Haney A, Jechura TJ, Moore FR, Bingman VP (2006) Daytime naps in night-migrating birds: behavioural adaptation to seasonal sleep deprivation in the Swainson's Thrush, Catharus ustulatus. Anim Behav 72:951-958. https://doi.org/10.1016/j. anbehav.2006.03.008

Gauthier-Clerc M, Tamisier A, Cézilly F (1998) Sleep-vigilance trade-off in green-winged teals (Anas crecca crecca). Can J Zool 76:2214-2218. https://doi.org/10.1139/z98-166

Gauthier-Clerc M, Tamisier A, Cézilly F (2000) Sleep-vigilance tradeoff in gadwall during the winter period. Condor 102:307-313. https://doi.org/10.2307/1369642

Gauthier-Clerc M, Tamisier A, Cézilly F (2002) Vigilance while sleeping in the breeding pochard Aythya ferina according to sex and age. Bird Study 49:300-303. https://doi.org/10.1080/0006365020 9461279

Hailman JP (1966) Another nocturnal gull? Audubon Mag 68:297 
Harris MP (1970) Breeding ecology of the Swallow-tailed gull. Auk 87(2):215-243. https://sora.unm.edu/sites/default/files/journals/ auk/v087n02/p0215-p0243.pdf

Harris SW (1974) Status, chronology, and ecology of nesting storm petrels in northwestern California. Condor 76:249-261. https:// doi.org/10.2307/1366338

Harrison C (1975) A field guide to the nests, eggs and nestlings of British and European birds. Collin Sons \& Co Ltd Glasgow, London

Hayes FE, Hayward JL (2020) Nocturnal copulation in Glaucouswinged Gulls Larus glaucescens. Marine Ornithol 48:55-59. https://digitalcommons.andrews.edu/cgi/viewcontent.cgi?artic le $=2239 \&$ context $=$ pubs

Hébert PN, McNeil R (1999) Nocturnal activity of Ring-billed gulls at and away from the colony. Waterbirds 22(3):445-451. https:// www.jstor.org/stable/1522122

Huber R, Rattenborg NC, Mandt BH, Benca RM, Obermeyer WH, Winsauer PJ, Wikelski M (2004) Migratory sleeplessness in the White-Crowned Sparrow (Zonotrichia leucophrys gambelii). PLoS Biol 2:e212. https://doi.org/10.1371/journal.pbio.0020212

Hunt GL Jr, Eppley Z, Drury WH (1981a) Breeding distribution and reproductive biology of marine birds in the eastern Bering Sea. In: Hood DW, Calder JA (eds) The Eastern Bering Sea Shelf: Oceanography and Resources. University of Washington Press, Seattle, pp 649-687. https://doi.org/10.5962/bhl.title.61718

Hunt GL Jr, Gould PJ, Forsell DJ, Peterson HJr (1981b) Pelagic distribution of marine birds in the eastern Bering Sea In: Hood DW, Calder JA (eds) The Eastern Bering Sea Shelf: Oceanography and Resources. University of Washington Press, Seattle, pp 689-718. https://doi.org/10.3402/polar.v8i1.6802

Indykiewicz P (2015) Egg losses caused by cold snap in the Blackheaded Gull (Chroicocephalus ridibundus L.). Pol J Ecol 63:460 466. https://doi.org/10.3161/15052249PJE2015.63.3.016

Indykiewicz P, Minias P (2019) A non-invasive method to reduce the negative impact of Black-headed Gulls Chroicocephalus ridibundus on the breeding success of Common Terns Sterna hirundo. Ardea 107(2):159-171. https://doi.org/10.5253/arde.v107i2.a3

Jakubas D, Indykiewicz P, Minias P, Kowalski J, Iciek T (2020) Intercolony variation in flight characteristics of black-headed gulls Chroicocephalus ridibundus during the incubating period. Ecol Evol 10:5489-5505. https://doi.org/10.1002/ece3.6291

Jessop TS, Limpus CJ, Whittier JM (2002) Nocturnal activity in the green sea turtle alters daily profiles of melatonin and corticosterone. Horm Behav 41:357-365. https://doi.org/10.1006/hbeh. 2002.1775

John TM, George JC, Yie SM, Brown GM (1993) Flight-induced increase in circulating levels of melatonin in the homing pigeon. Comp Biochem Physiol 106A:645-648. https://doi.org/10.1016/ 0300-9629(93)90374-D

Keitt BS, Tershy BR, Croll DA (2004) Nocturnal behavior reduces predation pressure on Black-vented Shearwaters Puffinus opisthomelas. Marine Ornithol 32:173-178. https://marineornithology.org/ $\sim$ marineor/PDF/32_2/32_2_173-178.pdf

Kempenaers B, Borgstrom P, Loes P, Schlicht E, Valcu M (2010) Artificial night lighting affects dawn song, extra-pair siring success, and lay date in songbirds. Curr Biol 20:1735-1739. https://doi. org/10.1016/j.cub.2010.08.028

Kruuk H (1964) Predators and anti-predator behavior of the Blackheaded Gull (Larus ridibundus L.). Behavior Suppl 11:1-129. https://www.jstor.org/stable/30039149

Kuznetsova A, Brockhoff PB, Christensen RHB (2017) lmerTest package: tests in linear mixed effects models. J Stat Softw 82:1-26

Leck CF (1971) Nocturnal habits of Ring-billed Gulls (Larus delawarensis) at Thimble Shoal. Virginia Chesapeake Sci 12:188. https:// doi.org/10.2307/1350783
Lendrem DW (1983) Sleeping and vigilance in birds. I. Field observations of the mallard (Anas platyrhynchos). Anim Behav 31:532538. https://doi.org/10.1016/S0003-3472(83)80076-1

Lendrem DW (1984) Sleeping and vigilance in birds. II. An experimental study of the barbary dove (Streptopelia risoria). Anim Behav 32:243-248. https://doi.org/10.1016/S0003-3472(84)80343-7

Leopold MF, Philippart CJM, Yorio P (2010) Nocturnal feeding under artificial light conditions by Brown-hooded gull (Larus maculipennsis) in Puerto Madryn Harbour (Chubut Province, Argentina). Hornero 25(2):55-60

Lesku JA, Rattenborg NC, Valcu M, Vyssotski AL, Kuhn S, Kuemmeth F, Heidrich W, Kempenaers B (2012) Adaptive sleep loss in polygynous pectoral sandpipers. Science 337:1654-1658. https:// doi.org/10.1126/science.1220939

Lima SL (2005) Sleeping under the risk of predation. Animal Behav 70(4):723-736. https://doi.org/10.1016/j.anbehav.2005.01.008

McNeil R, Drapeau P, Goss-Custard JD (1992) The occurrence and adaptive significance of nocturnal habits in waterfowl. Biol Rev 67:381-419. https://doi.org/10.1111/j.1469-185X.1992.tb01188.x

McNeil R, Drapeau P, Pierotti R (1993) Nocturnality in colonial waterbirds: Occurrence, special adaptations, and suspected benefits. In: Power DM (ed) Current Ornithology 10. Plenum Press, New York, pp 187-246. https://doi.org/10.1007/978-1-4615-9582-3_4

Meyer WE, Millam JR (1991) Plasma melatonin levels in Japanese quail exposed to dim light are determined by subjective interpretation of day and night, not light intensity. Gen Comp Endocrinol 82:377-385. https://doi.org/10.1016/0016-6480(91)90313-U

Minias P (2014) Evolution of within-colony distribution patterns of birds in response to habitat structure. Behav Ecol Sociobiol 68:851-859. https://doi.org/10.1007/s00265-014-1697-8

Mougeot F, Bretagnolle V (2000) Predation risk and moonlight avoidance in nocturnal seabirds. J Avian Biol 31:376-386. https://doi. org/10.1034/j.1600-048X.2000.310314.x

Nelson DA (1989) Gull predation on Cassin's Auklet with the lunar cycle. Auk 106:495-497. https://www.jstor.org/stable/4087878

Németh Z (2009) Observation of daytime sleep-like behavior in a migratory songbird during stopover. Wilson J Ornit 121:644-646. https://doi.org/10.1676/08-146.1

Nisbet ICT, Finch CE, Thompson N, Russek-Cohen E, Proudman JA, Ottinger MA (1999) Endocrine patterns during aging in the common tern (Sterna hirundo). Gen Comp Endocrinol 114:279-789. https://doi.org/10.1006/gcen.1999.7255

Pierotti R, Annett C (1987) Reproductive consequences of dietary specialization and witching in an ecological generalist. In: Kamil AC, Krebs J, Pulliam HR (eds) Foraging Behavior. Plenum Press, New York, pp 417-442. https://doi.org/10.1007/978-1-4613-1839-2_13

Pierotti R, Annett C (1990) Diet and reproductive output in seabirds. Bioscience 40:568-574. https://doi.org/10.2307/1311297

R Core Team (2019) R: A language and environment for statistical computing. Vienna, Austria: R Foundation for Statistical Computing. https://doi.org/10.1890/0012-9658(2002)083[3097:CFHIWS] 2.0.CO;2

Raap T, Sun J, Pinxten R, Eens M (2017) Disruptive effects of light pollution on sleep in free-living birds: season and/or light intensity-dependent. Behav Proc 144:13-19. https://doi.org/10.1016/j. beproc.2017.08.011

Rattenborg NC (2006) Do birds sleep in flight? Naturwissenschaften 93:413-425. https://doi.org/10.1007/s00114-006-0120-3

Rattenborg NC (2017) Sleeping on the wing. Interface. Focus 7(1):20160082. https://doi.org/10.1098/rsfs.2016.0082

Rattenborg NC, Mandt BH, Obermeyer WH, Winsauer PJ, Huber R, Wikelski M, Benca RM (2004) Migratory sleeplessness in the white-crowned sparrow (Zonotrichia leucophrys gambelii). PLoS Biol 2(7):e212. https://doi.org/10.1371/journal.pbio.0020212

Rattenborg NC, Martinez-Gonzalez D, Lesku JA (2009) Avian sleep homeostasis: convergent evolution of complex brains, cognition 
and sleep functions in mammals and birds. Neurosci Biobehav Rev 33:253-270. https://doi.org/10.1016/j.neubiorev.2008.08.010

Rattenborg NC, Voirin B, Cruz SM, Tisdale R, Dell'Omo G, Lipp H-P, Wikelski M, Vyssotski AL (2019) Evidence that birds sleep in mid-flight. Nat Commun 7:12468. https://doi.org/10.1038/ncomm s12468

Rechtschaffen A, Bergmann BM (2002) Sleep deprivation in the rat: an update of the 1989 paper. Sleep 25:18-24. https://doi.org/10. 1093/sleep/25.1.18

Russ A, Rüger A, Klenke R (2015) Seize the night: European Blackbirds (Turdus merula) extend their foraging activity under artificial illumination. J Ornithol 156:123-131. https://doi.org/10.1007/ s10336-014-1105-1

Shaw PJ, Tononi G, Greenspan RJ, Robinson DF (2002) Stress response genes protect against lethal effects of sleep deprivation in Drosophila. Nature 417:287-291. https://doi.org/10.1038/417287a

Smithson M, Verkuilen J (2006) A better lemon squeezer? Maximumlikelihood regression with beta-distributed dependent variables. Psychol Methods 11(1):54-71. https://doi.org/10.1037/1082989X.11.1.54

Snyder JM, Molk DM, Treuting PM (2013) Increased Mortality in a Colony of Zebra Finches Exposed to Continuous Light. J Am Assoc Lab Anim Sci 52:301-307. https://europepmc.org/article/ $\mathrm{pmc} / \mathrm{pmc} 3690453$

Steinmeyer C, Schielzeth H, Mueller JC, Kempenaers B (2010) Variation in sleep behavior in free-living blue tits, Cyanistes caeruleus: effects of sex, age and environment. Anim Behav 80:853-864. https://doi.org/10.1016/j.anbehav.2010.08.005

Tarburton MK (1991) Opportunistic nocturnal feeding by Silver Gulls. Aust Bird Watcher 14:31

Underhill G (1987) Grey-headed Gulls Larus cirrocephalus feeding on insects at night. Cormorant 15:95
Vandenabeele SP, Shepard EL, Grogan A, Wilson RP (2012) When three per cent may not be three per cent; device-equipped seabirds experience variable flight constraints. Mar Biol 159:1-14

Velando A, Freire J (2001) How general is the central-periphery distribution among seabird colonies? Nest spatial pattern in the European Shag. Condor 103:544-554. https://doi.org/10.1093/condor/ 103.3.544

Watanuki Y (1986) Moonlight avoidance behavior in Leach's StormPetrels as a defense against Slaty-backed Gulls. Auk 103:4-22. https://www.jstor.org/stable/4086959

Wikelski M, Tarlow EM, Eising CM, Groothuis TGG, Gwinner E (2006) Do night-active birds lack daily melatonin rhythms? A case study comparing a diurnal and a nocturnal-foraging gull species. J Ornithol 147:107-111. https://doi.org/10.1007/ s10336-005-0018-4

Yorio P, Quintana F (1997) Predation by Kelp Gulls Larus dominicanus at a mixed-species colony of Royal Terns Sterna maxima and Cayenne Terns Sterna eurygnatha in Patagonia. Ibis 139:536541. https://doi.org/10.1111/j.1474-919X.1997.tb04670.x

Yorio P, Suárez N, Quintana F, Gatto A (2005) Nocturnal activity in breeding Olrog's Gulls (Larus atlanticus). Ornit Neotropical $16: 123-126$

Ytreberg NJ (1956) Contribution to the breeding biology of the Blackheaded Gull [Larus ridibundus L.] in Norway. Oslo University Press, USA

Publisher's Note Springer Nature remains neutral with regard to jurisdictional claims in published maps and institutional affiliations. 